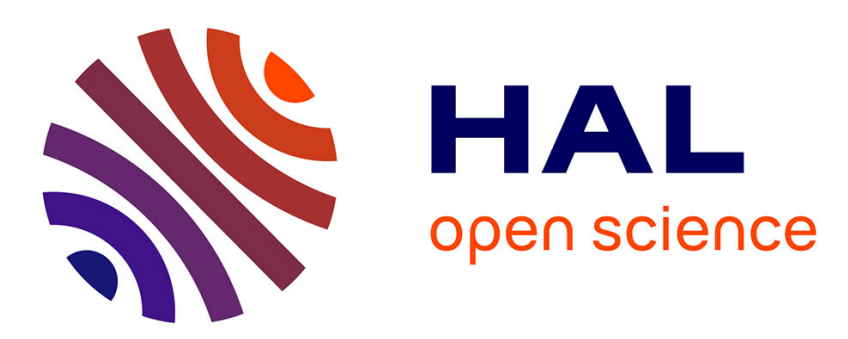

\title{
A reference method for the evaluation of femoral head joint center location technique based on external markers
}

Helene Pillet, Morgan Sangeux, Jérome Hausselle, Rami El Rachkidi, Wafa Skalli

\section{To cite this version:}

Helene Pillet, Morgan Sangeux, Jérome Hausselle, Rami El Rachkidi, Wafa Skalli. A reference method for the evaluation of femoral head joint center location technique based on external markers. Gait \& Posture, 2014, 39, pp.655-658. 10.1016/j.gaitpost.2013.08.020 . hal-01083830

\section{HAL Id: hal-01083830 https://hal.science/hal-01083830}

Submitted on 2 Apr 2015

HAL is a multi-disciplinary open access archive for the deposit and dissemination of scientific research documents, whether they are published or not. The documents may come from teaching and research institutions in France or abroad, or from public or private research centers.
L'archive ouverte pluridisciplinaire HAL, est destinée au dépôt et à la diffusion de documents scientifiques de niveau recherche, publiés ou non, émanant des établissements d'enseignement et de recherche français ou étrangers, des laboratoires publics ou privés. 


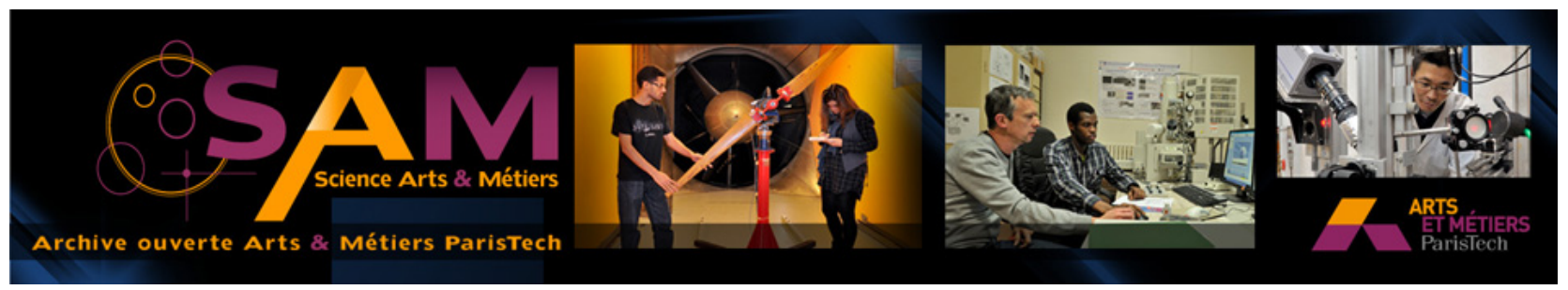

Science Arts \& Métiers (SAM)

is an open access repository that collects the work of Arts et Métiers ParisTech researchers and makes it freely available over the web where possible.

This is an author-deposited version published in: http://sam.ensam.eu

Handle ID: .http://hdl.handle.net/10985/8923

\section{To cite this version :}

Helene PILLET, Morgan SANGEUX, Jérome HAUSSELLE, Rami EL RACHKIDI, Wafa SKALLI $A$ reference method for the evaluation of femoral head joint center location technique based on external markers - Gait and Posture - Vol. 39, p.655-658 - 2014 


\title{
A reference method for the evaluation of femoral head joint center location technique based on external markers
}

\author{
Hélène Pillet ${ }^{\mathrm{a}, *}$, Morgan Sangeux ${ }^{\mathrm{b}, \mathrm{c}, \mathrm{d}}$, Jérôme Hausselle ${ }^{\mathrm{a}}$, Rami El Rachkidi ${ }^{\mathrm{a}}$, Wafa Skalli ${ }^{\mathrm{a}}$ \\ ${ }^{a}$ Arts et Metiers ParisTech, LBM, 151 bd de l'hopital, 75013 Paris, France \\ ${ }^{\mathrm{b}}$ Royal Children's Hospital, Melbourne, Australia \\ ${ }^{\mathrm{c}}$ University of Melbourne, School of Engineering, Australia \\ ${ }^{\mathrm{d}}$ Murdoch Children Research Institute, Melbourne, Australia
}

Keywords:

Biplanar X-rays

EOS

Gait analysis

Biomechanics

Joint center

\section{A B S T R A C T}

Accurate localization of joint centers is essential in movement analysis. However, joint centers cannot be directly palpated and alternative methods must be used. To assess the relative merits of these methods, a medical image based reference should be used. The EOS ${ }^{\circledR}$ system, a new low dose bi-planar X-rays imaging technique may be considered. The aim of this study was to evaluate the accuracy of hip joint center $(\mathrm{HJC})$ localization using the $\operatorname{EOS}^{\circledR}$ system. Seventeen healthy young adults participated in the study. Femoral heads and pelvic external markers were localized using the EOS $^{\circledR}$ system and the HJCs were expressed in the movement analysis coordinate system. Results showed that external marker localization was reliable within $0.15 \mathrm{~mm}$ for trained assessors. Mean accuracy for HJC localization was $2.9 \mathrm{~mm}$ (SD: 1.3, max: 6.2). The EOS based method therefore appeared reliable and may be used for femoral head localization or as a reference to assess the accuracy of other methods for HJC localization.

\section{Introduction}

An accurate method of joint center localization is essential for kinematic and kinetic calculations in movement analysis [1]. To estimate the location of the hip joint center $(\mathrm{HJC})$, previous studies have used predictive $[2,3]$, functional $[4,5]$ or medical image based [6-9] methods. Predictive and functional methods offer easy integration into existing clinical assessment but their accuracy needs to be established before implementation. Medical image based techniques may provide accurate 3D position of joint centers in the coordinate system of the imaging device. To be useful, these coordinates need to be registered to the pelvis coordinate system defined for movement analysis from external skin markers. This critical step raises two issues. First, when external markers were not available on the medical images, researchers have to assume that external markers were exactly positioned over bony landmarks that can be localized on the medical images. Any discrepancy between external markers positions and bony landmarks affects the accuracy of the HJCs coordinates in the pelvic coordinate system. Second, when external markers were available on the medical images, the subjects' posture in the imaging device may be different to the static calibration posture for movement analysis. For example, when the

\footnotetext{
* Corresponding author. Tel.: +33 144246338; fax: +33 144246366 E-mail address: helene.pillet@ensam.eu (H. Pillet).
}

subjects are lying supine [6] major bias may be expected from soft tissue artifact between the lying supine and standing up postures.

In this context, a new system, $\operatorname{EOS}^{\circledR}$ (EOS Imaging - France), based on low-dose bi-planar X-rays taken in a standing position [10] together with external motion capture markers may serve as a reference. Images from this system are used to reconstruct 3D bones models which can be registered to external markers and in the appropriate subject's posture for static calibration. It is then possible to assess the relationship between the external markers based coordinate systems and the bones models. In clinical routine, the systematic use of X-rays, even low dose (6-9 times less than conventional X-rays), remains problematic. However, depending on the accuracy, it may be suitable to validate alternative methods of HJCs localization. The aim of the present study was to evaluate the accuracy of hip joint center (HJC) localization using the $\operatorname{EOS}^{\circledR}$ system.

\section{Material and method}

\subsection{Subjects}

Seventeen volunteers ( 11 males and 6 females) were considered after informed consent and ethical committee approval. Subjects had a mean weight of $75.8 \mathrm{~kg}$ (range $54.3-102 \mathrm{~kg}$ ), mean height $1.74 \mathrm{~m}$ (range 1.52-1.92 $\mathrm{m}$ ) and Body Mass Indexes (BMI) ranged from 17 to 33 . 


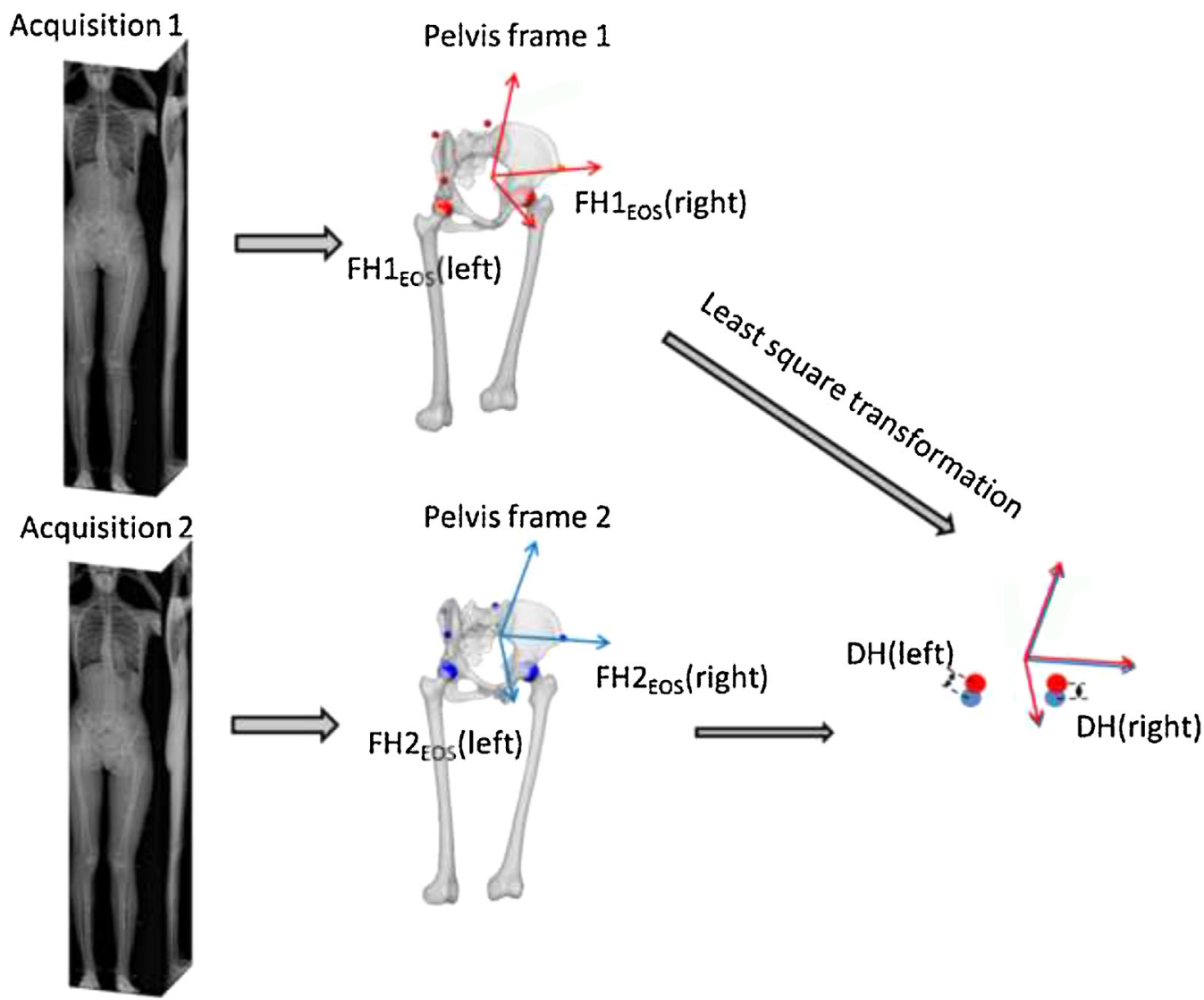

Fig. 1. Two pairs of radiographies for one subject (the first pair centered on the right lower limb and the second pair centered on the left lower limb). Pelvis markers are visible on both X-rays.

\subsection{Protocol}

Volunteers were equipped with four $14 \mathrm{~mm}$ reflective markers placed on the anterior and posterior iliac spine landmarks of the pelvis. For each subject, two acquisitions were taken with the EOS ${ }^{\mathbb{R}}$ (Fig. 1) in a standard standing posture described by Chaibi et al. [11]. Each acquisition consisted of two simultaneous X-ray images in the sagittal and coronal plane. Acquisitions were performed 5 min apart to allow the system to cool down. Three-dimensional reconstruction of the femur was performed as described by Chaibi et al. [11]. A sphere was fitted in the least square sense to the femoral head region of the model to localize the femoral head center in the EOS ${ }^{\mathbb{R}}$ coordinate system. Three dimensional positions of the pelvic markers were also computed: the projected images of a $14 \mathrm{~mm}$ diameter sphere model were manually adjusted on the two sets of bi-planar X-rays to match reflective markers contours.

\subsection{Repeatability of markers identification}

Data from 4 of the subjects were used ( 1 male and 1 female with a BMI $>25,1$ male and 1 female with a BMI $<25$ ). Markers from the first pair of images were considered. Two trained operators (bioengineers) independently placed three times the entire set of markers. The method described by Glüer et al. [12] was used to calculate the inter-operator repeatability of marker localization on the images.

\subsection{Accuracy of femoral head registration (Fig. 2)}

The right and left femoral heads were localized for each acquisition ( $\mathrm{FH}_{\mathrm{EOS} 1}$ and $\mathrm{FH} 2_{\mathrm{EOS} 2}$ ). We calculated the transformation to map the pelvic markers from the first acquisition to the second acquisition in the least square sense [13]. The transformation was then applied to the position of the femoral head from the first acquisition to map it onto the second acquisition which gives FH1 $1_{\text {EOS2 }}$. Accuracy of the femoral head registration was calculated as $\mathrm{D}_{\mathrm{FH}}$, the distance between $\mathrm{FH} 1_{\mathrm{EOS} 2}$ and $\mathrm{FH} 2_{\mathrm{EOS} 2}$. It should be noted that $\mathrm{D}_{\mathrm{FH}}$ includes accuracy of femoral head localization and repeatability of pelvis markers localization.

\section{Results and discussion}

Inter-operator variability in markers localization was $0.15 \mathrm{~mm}$. Uncertainty was mainly related to visibility of some of the markers due to bone or marker superposition, and sometimes to the lack of sphericity of the markers on the images. The distance $D_{\mathrm{FH}}$ was homogeneous for left and right HJC and $2.9 \mathrm{~mm}$ in average (SD: 1.3 ). There was only one outlier ( $6.2 \mathrm{~mm}$, Table 1, S8 left) over 34 measurements.

The EOS method appears more reliable than other published methods. In a recent study describing a 3D ultrasound method [14], authors reported an accuracy of $4 \mathrm{~mm}$ for the distance between the left and right femoral heads with respect to magnetic resonance imaging (MRI). However, since MRI images were taken lying supine and external motion capture markers cannot be seen on the images, the authors were unable to assess the accuracy of the femoral head localization with respect to the pelvic coordinate system. Leardini et al. used a similar technique based X-ray (called RSA) to compare the position of the HJC output by predictive and functional methods [4]. The authors reported a comparable accuracy for the marker localization $(0.2 \mathrm{~mm})$ from the RSA technique but did not report the accuracy of the femoral head localization. However, the technique described in Leardini et al study involves levels of ionizing radiation that are too high to be 

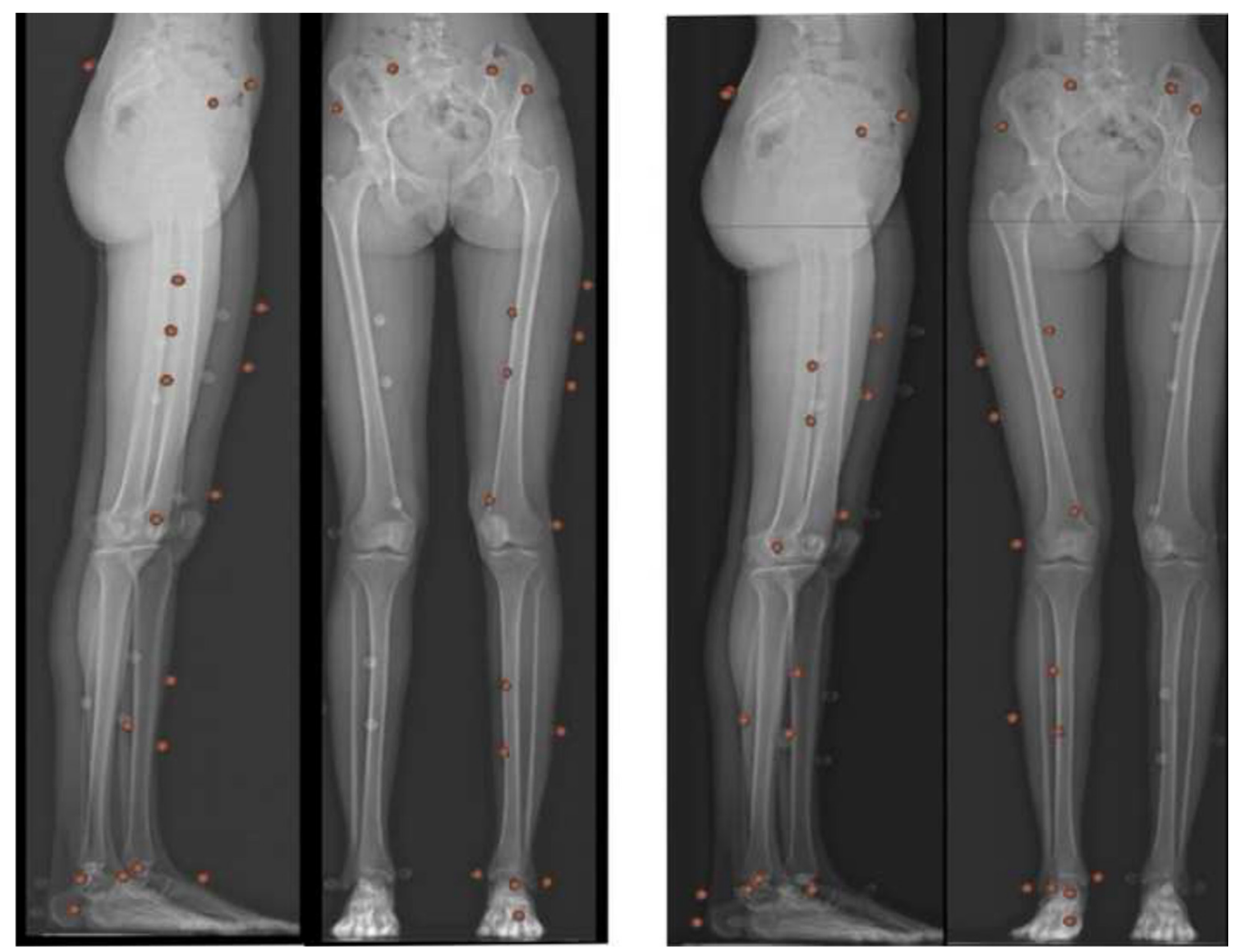

Fig. 2. Schematic of the process to obtain accuracy data.

used in extensive data collection and necessitated the use of tantalum balls instead of external markers. It is only since the EOS $^{\circledR}$ system, with low dose radiation, that such stereoradiography techniques may be envisaged for extensive studies.

Typical accuracy of non-image based methods to locate the hip joint center range from $13 \mathrm{~mm}$ to $30 \mathrm{~mm}$ [15]. The current technique, with an average and directly comparable accuracy of $2.9 \mathrm{~mm}$ in average seems appropriate to serve as a reference. A great advantage of this approach, i.e. simultaneous visualization of femoral head and external markers, is that it is not affected by

\section{Table 1}

Accuracy of pelvis markers based registration of the femoral head for 17 subjects: distance $(\mathrm{mm})$ between the femoral head registered from pelvis markers and the femoral head computed from the femur model for right and left sides.

\begin{tabular}{lll}
\hline Subjects & $\begin{array}{l}\text { Distance for the } \\
\text { right femoral head }(\mathrm{mm})\end{array}$ & $\begin{array}{l}\text { Distance for the left } \\
\text { femoral head }(\mathrm{mm})\end{array}$ \\
\hline 1 & 2.0 & 3.2 \\
2 & 3.7 & 3.6 \\
3 & 3.2 & 1.8 \\
4 & 3.3 & 2.7 \\
5 & 0.7 & 1.5 \\
6 & 2.8 & 1.7 \\
7 & 2.1 & 1.5 \\
8 & 3.0 & 6.2 \\
9 & 1.0 & 1.8 \\
10 & 4.5 & 4.4 \\
11 & 0.9 & 2.5 \\
12 & 3.8 & 2.8 \\
13 & 4.7 & 4.5 \\
14 & 4.2 & 2.1 \\
15 & 4.1 & 3.7 \\
16 & 1.7 & 3.0 \\
17 & 3.0 & 3.6 \\
Mean & 2.9 & 3.0 \\
Max & 4.7 & 6.2 \\
\hline
\end{tabular}

subject specificities such as BMI or unusual anatomy. It therefore constitutes a strong base either for direct measurement of the hip joint center or for evaluation of alternative methods of estimation.

\section{Acknowledgments}

The authors are grateful to VICON (OMG-UK) for the loan of a motion capture system necessary for the overall study.

\section{Conflict of interest statement}

The authors do not have any financial or personal relationships with other people or organizations that could inappropriately influence the manuscript.

\section{References}

[1] Stagni R, Leardini A, Cappozzo A, Benedetti MG, Cappello A. Effects of hip joint centre mislocation on gait analysis results. J Biomech 2000;33:1479-87.

[2] Bell AL, Pedersen DR, Brand RA. A comparison of the accuracy of several hip center location prediction methods. J Biomech 1990;23:617-21.

[3] Davis RB, Ounpuu S, Tyburski D, Gage JR. A gait analysis data collection and reduction technique. Hum Mov Sci 1991;10:575-87.

[4] Leardini A, Cappozzo A, Catani F, Toksvig-Larsen S, Petitto A, Sforza V, et al. Validation of a functional method for the estimation of hip joint centre location. J Biomech 1999;32:99-103.

[5] Ehrig RM, Taylor WR, Duda GN, Heller MO. A survey of formal methods for determining functional joint axes. J Biomech 2007;40:2150-7.

[6] Otake Y, Suzuki N, Hattori A, Hagio K, Sugano N, Yonenobu K, et al. Fourdimensional model of the lower extremity after total hip arthroplasty. J Biomech 2005;38:2397-405.

[7] Kawakami H, Sugano N, Yonenobu K, Yoshikawa H, Ochi T, Hattori A, et al. Gait analysis system for assessment of dynamic loading axis of the knee. Gait Posture 2005;21:125-30.

[8] Ohnishi T, Suzuki M, Nawata A, Naomoto S, Iwasaki T, Haneishi H. Threedimensional motion study of femur, tibia, and patella at the knee joint from biplane fluoroscopy and CT images. Radiol Phys Technol 2010;3:151-8. 
[9] Sholukha V, Leardini A, Salvia P, Rooze M, Sint SV. Double-step registration of in vivo stereophotogrammetry with both in vitro 6-DOFs electrogoniometry and CT medical imaging. J Biomech 2006;39:2087-95.

[10] Dubousset J, Charpak G, Skalli W, Deguise J, Kalifa G. EOS: A new imaging system with low dose radiation in standing position for spine and bone \& joint disorders. J Musculoskelet Res 2010;13:1-12.

[11] Chaibi Y, Cresson T, Aubert B, Hausselle J, Neyret P, Hauger O, et al. Fast 3D reconstruction of the lower limb using a parametric model and statistical inferences and clinical measurements calculation from biplanar X-rays. Comput Methods Biomech Biomed Eng 2012;15:457-66.
[12] Glüer CC, Blake G, Lu Y, Blunt BA, Jergas M, Genant HK. Accurate assessment of precision errors: how to measure the reproducibility of bone densitometry techniques. Osteoporos Int 1995;5:262-70.

[13] Söderkvist I, Wedin PA. Determining the movements of the skeleton using well-configured markers. J Biomech 1993;26:1473-7.

[14] Peters A, Baker R, Sangeux M. Validation of 3-D freehand ultrasound for the determination of the hip joint centre. Gait Posture 2010;31:530-2.

[15] Sangeux M, Peters A, Baker R. Hip joint centre localization: evaluation on normal subjects in the context of gait analysis. Gait Posture 2011;34: 324-8. 